Revista Iberoamericana, Vol. LXXIV, Núm. 225, Octubre-Diciembre 2008, 943-957

\title{
SILVIANO SANTIAGO, ESTUDOS CULTURAIS E ESTUDOS LGBTS NO BRASIL
}

\author{
POR \\ DenILSON LOPES \\ Universidade de Brasília
}

Se o século xx foi o século das mulheres, o que não quer dizer que não haja muito ainda por avançar em matéria de conquista de direitos e valores, o século xxI bem pode ser aquele em que a homossexualidade se institucionaliza e se estabiliza socialmente. No Brasil dos anos noventa, jornais e telenovelas exploraram mais o tema, embalados pela polêmica suscitada em torno do projeto de união civil entre pessoas do mesmo sexo, apresentado pela então deputada federal Marta Suplicy. O movimento LGBTS ${ }^{1}$ politicamente engajado se ampliou, contando hoje com mais 170 grupos, sendo a grande maioria filiada à ABGLT (Associação Brasileira de Gays, Lésbicas, Travestis e Transexuais). Paradas do orgulho gay e eventos similares passaram a acontecer em diversas cidades do país. Só São Paulo em 2004 reuniu mais de 1 milhão e 500 mil participantes na sua parada.

Na universidade, não poderia ser diferente. Nos anos noventa, começa a se falar em estudos gays e lésbicos, ainda que desde o século xIx, quando o termo homossexualidade surgiu, ele tenha despertado o interesse de intelectuais no Brasil, mas como área de estudos só começa a ganhar visibilidade muito recentemente dentro da universidade.

Não pretendo fazer um levantamento histórico dos estudos LGBTS, mas apenas pontuar alguns aspectos que talvez sejam importantes para ajudar a compreender em que medida a contribuição de Silviano Santiago para este debate.

A partir dos anos setenta, diante da abertura política, o movimento LGBTS se desenvolve no Brasil, tendo um papel decisivo na quebra de preconceitos contra a homossexualidade. Em 1985, a homossexualidade deixa de ser considerada doença pelo Conselho Federal de Medicina. Em 1999, o Conselho Federal de Psicologia estabelece normas para coibir a promessa de "cura" para homossexualidade ainda praticada por alguns profissionais. Quanto ao ponto de vista jurídico, começa a haver um movimento em vários municípios e estados para incluir leis que proíbam

1 Lésbicas, Gays, Bissexuais, Transgêneros e Simpatizantes. 
a discriminação por orientação sexual. Embora a homossexualidade não fosse crime desde 1830, isto nunca impediu de se usar subterfúgios legais para coibir a expressão pública eprivada de afetos entre pessoas do mesmo sexo. Jáa esfera religiosa, sobretudo entre as igrejas cristãs hegemônicas no Brasil, é onde a quebra de preconceitos tem menos evoluído, apesar do esforço de discussão de indivíduos isolados, sendo o principal, senão único, discurso forte que entrava e sustenta a homofobia.

Também, já a partir dos anos setenta, na universidade, alguns antropólogos interessados não mais só em pensar sociedades pré-modernas e não-ocidentais, mas em estudar o cotidiano urbano, a partir de um conceito de cultura que pudesse transitar desde obras literárias de valor estéticos a práticas coletivas, colocam a homossexualidade sob um outro ângulo, contribuindo para liberá-la de preconceitos médicos, jurídicos e religiosos, como nos trabalhos de Peter Fry, Edward Macrae, Luiz Mott, Carlos Alberto Messeder Pereira e, mais recentemente, Maria Luíza Heilborn. ${ }^{2}$ Talvez seja no intervalo entre a história e antropologia, presente no trabalho destes autores, que podemos compreender recentes publicações como Além do Carnaval de James Green, a reedição ampliada de Devassos no Paraíso de João Silvério Trevisan, O Que é Lesbianismo de Tânia Navarro Swain e Abaixo do Equador de Richard Parker. Para quem trabalha com arte, o estudo dessas obras é fundamental para evitar uma transposição direta de modelos eurocêntricos ou norte-americanos, bem como por apontar para um conceito de cultura que integre as produções massivas, populares e eruditas, práticas coletivas e obras autorais, num mesmo espaço.

Neste quadro, algumas questões se colocam. O fim da revista Sui Generis, tentativa de fazer uma revista cultural para um público gay, bem como a dificuldade de distribuição que a editora GLS (abreviação para gays, lésbicas e simpatizantes) tem enfrentado, aponta ou não para as limitações mercadológicas da questão gay no Brasil? Seria a maior presença da questão gay na grande imprensa e a criação de coleções em grandes editoras como a Contra.Luz na Record e a Aletheia na Brasiliense, que acolhem esta produção diluidoras de um mercado específico? Como avaliar o sucesso de uma revista de nus masculinos como a $G$ que atinge também um público feminino? Ou a repercussão do filme Madame Satã de Karim Aïnouz para muito além de um audiência LGBTS?

De qualquer forma, é fundamental pensar a pertinência do termo "estudos gays e lésbicos" ou estudos LGBTS, até que ponto sua institucionalização é necessária ou desejável. Nomear é sempre um perigo, mas se não nos nomeamos,

2 A fim de não sobrecarregar a bibliografia, citarei apenas os livros de análise que tenham a ver diretamente com questões de cultura e arte. Ao leitor mais próximo da história e das ciências sociais, remeto ao livro Além do Carnaval de James Green que possui um levantamento bastante atualizado da produção brasileira e brazilianista nesta área. 
outros o farão. Dar um nome não significa simplesmente classificar, mas explorar, problematizar. Falar em teoria queer é fugir da discussão, sem desmerecer suas importante contribuições a este debate. A falta de tradução lingüística bem pode ser um indício da falta de tradução intelectual. Está sempre presente "o perigo constante na tradução de qualquer informação cultural advinda de registro lingüístico minoritário: a tendência a reduzir as distinções de identidade, assim apagando as distinções sutis que são o epicentro de seu sistema significante” (Larkosh). Há que se refletir sobre a opção do Festival Mix de sexualidades múltiplas, que percorre o Brasil em várias cidades e o termo GLS ou ainda a tônica do homoerotismo, termo clássico, colocado novamente em circulação no Brasil pelo psicanalista Jurandir Freire Costa, com eco nos estudos universitários, mas praticamente não utilizado entre os militantes. Os debochados e coloquiais bicha, viado ou a construção transnacional de uma homocultura ou do gay? A saída não está em apontar para um nome único, mas estratégias diferenciadas em função de realidades culturais e regionais distintas.

Pessoalmente, acho que a aliança com os estudos culturais é de vital importância para evitar um fechamento intelectual, para compor espaços que nos dêem visibilidade e espessura. Não se trata de uma adesão incondicional ao modelo culturalista norte-americano, mas a necessidade fundamental de ir além de uma guetização epistemológica, procurando um adensamento teórico e crítico, que conduz a um embate com diversas perspectivas de ponta nos debates contemporâneos. Énecessário não perder de vista que toda identidade é relacional. O redimensionamento da homossexualidade implica repensar a heterossexualidade, bem como a transitividade sexual historicamente presente na cultura brasileira, muito antes do boom bissexual dos anos setenta, que, se nunca impediu a violência homofóbica, não pode ser reduzida à alienação, ao enrustimento. Pensar a sexualidade e a afetividade implica discutir formas de adesão a projetos coletivos e temas que transitem para o conjunto da sociedade civil, como a tentativa de militantes brasileiros de incluir mais decisivamente o preconceito contra homossexuais no espectro da luta por direitos humanos fundamentais, dentro de uma sociedade mais justa para todos, como vem sendo feito com mais sucesso em relação à AIDS e a seus portadores.

O lançamento recente de A Conveniência da Cultura de George Yúdice é uma boa oportunidade para refletir sobre os desdobramentos dos Estudos Culturais no Brasil para além de sua matriz marxista na Escola de Birminghan, que incorporou criativamente nos EUA o pensamento da diferença francês e o grande boom dos movimentos políticos minoritários, e por fim, estabeleceu um rico diálogo com a produção de comparatistas latino-americanos, em que a produção crítica e artística contemporâneas brasileiras têm um papel de destaque, como a obra de Silviano Santiago, cujo também recente lançamento de seu Cosmopolitismo do Pobre reafirma esta interlocução. 
Parece já um lugar-comum mencionar mas necessário lembrar que depois de quinze anos sem lançar um livro de ensaios, Silviano Santiago retorna com $O$ Cosmopolitismo do Pobre, primeiro de uma serie de três volumes que certamente o recoloca no lugar de um dos ensaístas e críticos de cultura e da arte mais importantes da América Latina. Nestes quinze anos, que coincidiram com seus últimos anos na universidade antes da aposentadoria e uma intensa publicação de livros de ficção (Uma História de Família, 1992; Uma Viagem ao México e Cheiro Forte, 1995; Keith Jarrett no Blue Note, 1996; De Cócoras, 1999; O Falso Mentiroso, 2004) e apesar da intensa produção acadêmica e jornalística, sua imagem pública pendeu para o ficcionista, o escritor. Mas o ficcionista talvez tenha deixado marcas nestes ensaios que agora lemos em livro em que cada vez mais as teses são desdobradas por narrativas, situações que alargam e fragmentam um núcleo, deixando mais provocações, inquietações do que conclusões fechadas.

É bem verdade que não se pode separar seus ensaios de sua ficção. De certa forma, há questões que atravessam sua obra por inteiro. Como não entender que o posicionamento de abertura frente ao diálogo latino-americano em seu clássico ensaio “Entre-Lugar do Discurso Latino-Americano" publicado em Uma Literatura nos Trópicos não encontra uma contrapartida na viagem de Artaud ao México ficcionalizada? Ou que os dilemas do intelectual modernista não sejam redimensionados pelo seu retrato de um Graciliano Ramos atualizado pela ditadura dos anos sesenta de Em Liberdade e aqui, neste livro, na genealogia, em "Atração do Mundo”, pela criativa análise de Joaquim Nabuco e Mario de Andrade não como dois pólos opostos no nosso cenário intelectual mas posicionamentos que se suplementam, para usar o termo derrideano que lhe é caro, e se tensionam para compreender nossas atitudes até hoje entre o cosmopolitismo e o nacionalismo?

A opção pelo ensaio, pela intervenção nos jornais, por palestras produz, ao mesmo tempo, uma obra em aberto, que aceita os desafios do presente, mas ao mesmo tempo refaz nossa história cultural a partir de um ponto de vista alternativo à linhagem canônica e modernista uspiana da Antonio Candido e Roberto Schwarz, que se cristalizou numa crítica materialista, centrada numa dialética entre a arte e sociedade e na preocupação adorniana com a forma e que confunde mal-estar com atitude crítica.

A obra de Silviano Santiago redimensiona a tradição intelectual brasileira a partir de um ecletismo teórico que incorpora o impacto do pensamento da diferença, sobretudo Derrida, mas também Foucault e Deleuze; passando pelo debate sobre a pós-modernidade até o diálogo fecundo com os Estudos Culturais. Tudo reaparece de forma sutil e criadora neste seu último livro. Como estratégia, recusa tanto ficar à sombra dos grandes mestres, ser comentador bem comportado como o faz, por exemplo, Leyla Perrone-Moisés em relação a Barthes, canonizando esta tradição francesa. Silviano Santiago desloca o pensamento destes autores para fora de um 
cânone moderno e os faz vivos, atuantes, políticos, equivalente ao que Gayatri Spivak, Homi Bhabha fizeram nos EUA, ao relerem o pensamento francês da diferença .Também não se trata de um mergulho conceitual, de natureza filosófica, mas talvez uma atitude mais produtiva quando se é um intelectual nascido numa província ultramarina, que é menos a de um teórico, como de seu colega de geração, Luiz Costa Lima, e mais de um crítico e leitor que seguem os conceitos à medida em que os próprios textos os solicitam.

Para quem tanto defende a diversidade, a multiplicidade, o deslocamento; é interessante inventariar certas obsessões neste jogo constante entre a memória e a inserção neste lugar móvel, transnacional e midiático que emerge na segunda metade do século passado; o olhar atento e fascinado pelo presente, sem medo de se expor às fragilidades de modismos, correndo riscos, afirmando ainda uma vez mais, a partir de Nietzsche e da Contracultura, a alegria do estar presente, com todas suas impurezas e dilemas, mesmo com ironia, que se traduz no encerramento do livro em "Epílogo em 1 1. pessoa", espécie de autobiografia ficcional de um intelectual que vive á altura de nossas riquezas e fragilidades.

Em Cosmopolitismo do Pobre, o autor reafirma o movimento iniciado em seu clássico e já citado "O Entre-Lugar do Discurso Latino-Americano”, ao pensar alternativas aos grandes sistemas totalizantes, homogeneizados e excludentes, tenham estes os nomes de capitalismo ou nação, mas sem perder um posicionamento e engajamento em um mundo já então pós-utópico, nem cair no desespero da dualidade revolução ou barbárie. Em tempos difíceis, como o nosso, sem revolução, mas não sem esperanças, a obra de Silviano Santiago continua sendo uma referência, um farol para se compreender o Brasil após a ditadura, crítico do imobilismo consumista, realizando uma política do fragmento e da diversidade, mas sem cair em guetização particularista. O entre-lugar, longe de uma abstração, é um espaço central para compreender não só o posicionamento dos intelectuais em viagens geográficas, intelectuais e de formação, mas para lidar com o deslocamento de grandes contingentes da população mundial em busca de sobrevivência e emprego, como se apresenta no ensaio que dá título ao livro. Para além de uma noção exclusivamente classista, também aqui a questão negra e índia, já colocadas em seu programa trinta anos atrás retornam somadas a uma preocupação de gênero, que se traduz em “O Homossexual Astucioso", ensaio novamente em continuidade com sua ficção de Stella Manhattan e Keith Jarrett no Blue Note, na busca de uma alternativa tanto a uma perspectiva norte-americana, mas que não silencia nem reduz os novos sujeitos sociais e políticos. O entre-lugar é o espaço político e existencial, local e transnacional, de afetos e memórias.

A condição estrangeira se dissemina e se massifica, diante dos cada vez mais intensos fluxos migratórios que atravessam o planeta. Nesse contexto, o que pretendo 
tratar não é tanto da experiência de mal-estar do intelectual moderno exilado, devido a dificuldades políticas e/ou pela perda de papel social no seu país. Também não se trata mais do horizonte existencialista, pós-Segunda Guerra Mundial, em que o estrangeiro assume um posição universalizante, metáfora da experiência humana, em que todos somos estrangeiros onde quer que estejamos, estranhos diante de um mundo que não carrega mais sentidos transcendentes, como em A Náusea da Sartre. É claro que estas duas construções ainda estão presentes neste fim de século, mas gostaria de produzir um deslocamento culturalista. Em Keith Jarret no Blue Note, Silviano Santiago apresenta personagens urbanos, de classe média, não marcados por perseguições políticas, nem por uma excepcionalidade mitificadora das margens, também já distantes os laivos contraculturais. Também esta experiência estrangeira se traduz em pequenas circunstâncias cotidianas (trocadilhos não compreendidos, gestos reprovados etc) em que o confronto e diálogo com o outro se dá de uma forma direta. Pequenas dores, pequenas alegrias. Nada de dilaceramentos diante dos absurdos do mundo, nem de confrontos identitários muito óbvios. O recuo para a intimidade não implica uma alienação, mas um tom menor.

Se os Estudos Culturais estão nos fazendo repensar a literatura brasileira, a partir deum fraturamento daidentidadenacional, tornando esta mais descentrada, na medida em que são colocadas em pauta noções como hibridismos, fronteiras flutuantes, derivas gendéricas, que servem para reler autores canônicos da modernidade (como Clarice Lispector), resgatar outros esquecidos (como Samuel Rawet), bem como estabelecer diálogos com obras que têm enfatizado o olhar estrangeiro como forma de construção artística, ${ }^{3}$ gostaria de falar de um lugar bem preciso. Lembro que há uma presença recorrente em homotextos da presença da viagem, da busca de ir ao estrangeiro para encontrar um outro lar, romance, companheirismo ou sexo (Fichte xiii). Como sintetiza Hubert Fichte: "a viagem é uma necessidade sexual - escritura e descoberta" (idem, 335). A partir deste mote, comento Keith Jarret no Blue Note de Silviano Santiago a partir das relações estabelecidas entre homens diante dos fluxos interculturais. Esta experiência homoafetiva, com especial ênfase nos frágeis limites do amor e da amizade, se coloca numa situação permanentemente intervalar, para além de uma identidade homossexual ou de uma sensibilidade homoerótica. Este entre-lugar articula personagens em que sua nacionalidade e sexualidade se apresentam entrelaçadas e em trânsito.

A nação é uma experiência que se "produz um deslizamento contínuo de categorias, como sexualidade, afiliação de classe, paranóia territorial ou 'diferença

3 Entre outras, cito Rastros de Verão de João Gilberto Noll, Senhorita Simpson de Sérgio Sant'Anna, Postcards de Marilene Felinto, Ana em Veneza de João Silvério Trevisan, Relato de um Certo Oriente de Milton Hatoum, Teatro de Bernardo Carvalho, Nur na Escuridão de Salim Miguel e O Marciano de Felipe Nepomuceno. 
cultural' no ato de escrever a nação" (Bhabha, O Local da Cultura 200). Como nos lembra Anne McClintock: "os nacionalismos são genderizados, inventados e perigosos” (89), no sentido em que eles representam relações com o poder político e com as tecnologias de poder (idem). A nação é uma experiência de identificação compartilhada (idem) que paira sobre nós, como sistemas que legitimam o acesso ao Estado-Nação, estabelecendo inclusões e exclusões. Ainda que nossas sensibilidades sejam definidas cada vez mais por fronteiras, mais ou menos frágeis, e fluxos culturais, é importante lembrar que o nacionalismo deriva de uma memória, humilhação e esperança masculinizadas (idem). E se as mulheres, no período de formação de nossa literatura, ainda entravam como símbolo, mas não como agentes (idem, 90); nós, homossexuais, invisíveis e/ou indesejáveis, obviamente não chegamos sequer a ser símbolos nacionais e muito menos agentes, fomos e somos excluídos de espaços legítimos de reprodutibilidade e socialização, marcados pela falta de legitimidade de famílias gays com filhos e pela dificuldade de estabelecimento de modelos sociais alternativos inter-geracionais de forma estável. Por issoé importante repensar as culturas nacionais a partir das minorias destituídas. ${ }^{4}$ Seu efeito mais significativo não é a proliferação da história dos excluídos, mas fortalece uma base para o estabelecimento de conexões internacionais (Bhabha, O Local da Cultura 25). Na construção de suas múltiplas fronteiras, a nação entendida como experiência narrada tem na escrita afetiva uma base importante mesmo para a adesão e a ação social. Trata-se não só "simplesmente de mudar as narrativas de nossas histórias, mas transformar nossa noção do que significa viver, do que significa ser, em outros tempos e espaços diferentes” (idem, 352).

Mas o "que se há de fazer em um mundo onde mesmo quando você é uma solução você é um problema” (Toni Morrison apud idem, 351)? A solidão dos personagens de Silviano após a morte dos companheiros ${ }^{5}$ e da pouca presença dos amigos homo ou heterossexuais dá o tom da literatura brasileira contemporânea na quase ausência de relações amorosas estáveis entre homens. A invisibilidade do homossexual o impediu de ter um papel claro na cultura nacional ou resultou de uma submissão à dualidade gendérica masculino/feminino, com sutis formas de resistência, sobrevivência e recolhimento no espaço privado ou nos guetos. Não estou reduzindo o discurso literário ao político, mas tentando uma leitura política do literário, sem que uma esfera se submeta a outra. Não estou falando aqui de noções abstratas de diferença e identidade, mas de uma experiência que se traduz

4 Se relação entre cultura nacional e identidade feminina vem sendo bastante desenvolvida, o mesmo não pode ser dito de sua relação com a homossexualidade, mas consultar Lauren Berlant e Elizabeth Freeman (1994), Lee Edelman (1994) e Arnaldo Cruz-Malavé (1998). No Brasil, é um campo realmente a ser explorado.

5 “Amizade construída duma maneira adulta e egoísta como só dois solteirões podem construí-la sem os entraves da esposa, dos filhos e das constantes reuniões familiares” (123). 
numa alegria de pertencer e compartilhar, numa alegria ao se constituir como intelectual particular, anverso da construção do intelectual moderno, seja isolado, exilado, seja revolucionário, engajado, porta-voz. É este espaço modesto o meu lugar possível de fala agora.

Não mais o tom empenhado, quase engajado, de "O Entre-Lugar do Discurso Latino Americano", ${ }_{6}^{6}$ mas uma certa deriva entre fronteiras e barreiras que se multiplicam e se deslocam. Silviano Santiago, trinta anos depois de seu ensaio clássico, se recolhe, se afasta cada vez mais da figura de um intelectual maior. Tempo de projetos menores, pensamentos débeis, sensibilidades frágeis para o presente. $\mathrm{O}$ narrar, a experiência substituem as polêmicas de uma universidade que cada vez mais se profissionaliza e se autolegitima. A cada vez mais visibilidade do escritor diante do ensaísta parece reafirmar esta escolha por uma política do afetivo. Nestes contos, o entre-lugar não é só um espaço frágil do intelectual e das produções periféricas, mas a base de uma política e estética da amizade, de uma ética particularista da deriva, do desejo e do encontro.

A obra de Silviano Santiago contribuiuparareafirmarqueminhas responsabilidades como intelectual, gay ebrasileiro não podem se restringir ao de um intelectual orgânico, vinculado a um grupo social, sem levar em consideração complexos processos de exclusãoe inclusão social. Não se trata de buscar aceitação eintegraçãonuma sociedade injusta, em que o termo gay se restrinja a só mais um rótulo numa sociedade de segmentação de mercado ou mais um elemento na construção do homossexual como bom moço, apenas desejando andar de braço dados com seu namorado pelas ruas, ter filhos e ir para o Exército. Não sei se é o caso de recuperar uma tônica libertária ou radical, o que pode parecer ingênuo ou simplesmente ineficiente, mas certamente me sinto incomodado ao ver como cada vez mais o termo gay parece mais um item banal na nossa classe média com complexo de Miami ou de New York, propalador de um consumismo desenfreado e de um ethos conservador.

Os riscos, que julgo necessários, da visibilidade pública da homossexualidade estão certamente em pensar esta construção como isolada e desvinculada das ansiedades de nossa época, mas se entendemos esta politização do privado, de resto empreendida por vários grupos minoritários, excluídos, como uma possibilidade de maior vínculo ao mundo, de busca de formas de pertencimento, em meio ao cinismo, à intolerância e ao ceticismo que parecem grassar, ela só pode trazer benefícios para a construção de uma sociedade mais justa e democrática. O grande desafio dos militantes e estudiosos no Brasil é de colocar a questão da homossexualidade não só como algo que diga respeito a um grupo específico, mas ao conjunto da sociedade. $\mathrm{O}$ desafio nãoémais simplesmente produzir imagens positivas, mas proliferarnarrativas

6 "Falar, escrever, significa: falar contra, escrever contra” (Santiago, “O Entre-Lugar do Discurso...” 19). 
plurais na sociedade, para não só aprender com o que somos, mas também com o que não somos.

Na busca de referências intelectuais com que pudesse lidar com estes impasses na arte, o encontro com a obra de Silviano Santiago, especialmente a partir da leitura de seu romance Stella Manhattan me fez mudar de rota. Talvez nenhum outro crítico de cultura, entre os mestres de minha geração tenha nos trazido tantas sugestões para a construção dos estudos gays no Brasil do que Silviano Santiago. Desde, "O Entre-lugar do discurso latino-americano”, agora reeditado em português e em inglês, diferente de uma perspectiva marxista, que vai insistir, anos oitenta adentro, exclusivamente na exclusão por classe social, como Roberto Schwarz no seu "Nacional por Subtração", 7 Silviano Santiago descortina o horizonte de uma sociedade em que outras diferenças foram excluídas, como o índio e o negro, estabelecendo um diálogo fecundo entre Brasil e América hispânica, que cada vez fica mais relevante, face aos desafios do Mercosul, da Alca e da hispanização dos EUA.

Mais recentemente, quando discutia com alunos e professores da UERJ, parafraseando Murilo Mendes que se dizia escritor, católico; Silviano se apresentou como escritor, gay, unindo substantivamente sua escrita a sua orientação sexual, mas como aparece em "O Homossexual Astucioso", recusando a vitimização e o "exibicionismo público, protestante, exigido do homossexual pelos movimentos militantes norte-americanos" (14) e defendendo a busca de formas mais sutis de militância do que a política do outing. Silviano se pergunta no final: "Se a subversão através do anonimato corajoso das subjetividades em jogo, processo mais lento da conscientização, não adiciona melhor ao futuro diálogo entre heterossexuais e homossexuais, do que o afrontamento aberto por parte de um grupo que se automarginaliza, processo dado pela cultura norte-americana como mais rápido e eficiente?” (idem 15-16).

Ao dissociar o conhecido lema do movimento gay norte-americano silêncio=morte, Silviano aponta, sem explicitar, para uma política ambígua, tão ambígua como as práticas dos sujeitos nômades da contemporaneidade. Como bom intelectual empenhado, não se trata de formular programas de ação; e a positivização de nosso entre-lugar não conduz a uma visão ufanista do Brasil como paraíso sexual, nem também a um mal-estar adorniano, tão presente na tradição uspiana. A abertura para as diferenças afirma a alegria, para além do ressentimento e do catastrofismo, contrapõe-se à desmobilização cínica. Aalegria dialoga perfeitamente com a emergência de práticas e sujeitos políticos, dos movimentos minoritários às ONGs eàs discussões sobre ética na política e solidariedade na sociedade. Para além dos partidos políticos e sindicatos, o que está em pauta é a reafirmação do vínculo

\footnotetext{
7 Para uma leitura comparativa da crítica de Roberto Schwarz e Silviano Santiago, ver Eneida Leal Cunha (1997).
} 
entre a vida cotidiana e o conjunto da sociedade, criticando, senão suspendendo os limites clássicos entre o público e o privado, tais como foram definidos nas sociedades européias do séculoxviII exıx. A politização do privado não se resume à discussão da vida íntima de governantes, mas à recriação de formas mais afetivas de adesão ao coletivo.

Para não repetirmos perspectivas que apenas procuram nas artes representações da homossexualidade existente na sociedade, seria necessário ler com atenção os esforços da crítica brasileira e brazilianista, desde os trabalhos pioneiros, de caráter mais geral e mesmo jornalístico, feitos geralmente fora da universidade, como Jacarés e Lobisomens (1983) de Herbert Daniel e Leila Míccolis, Uma Flor para os Malditos (1984) de Maria Lúcia Faury, Devassos no Paraíso (1985) de João Silvério Trevisan, Um Tema Crucial (1989) de Paulo Hecker, até a atual geração de críticos literários, já mais marcados pelos estudos gays e lésbicos norte-americanos, que, pouco a pouco, a partir de artigos esparsos vem constituindo um espaço de discussão que levou a criação da Associação Brasileira de Estudos da Homocultura (ABEH), com nomes como José Carlos Barcelos, Mário Lugarinho, Marcelo Secron Bessa, Fernando Arenas, Ricky Santos, José Luís Foureaux, Eliane Berutti, Antônio Eduardo de Oliveira, Kátia Bezerra, Deneval Azevedo, reunidos em A Escrita de Adé, a que se somam nomes de geração anterior, mas com importantes contribuições, como Ítalo Moriconi, Maria Consuelo Cunha Campos, Víctor Hugo Adler Pereira e Raul Antelo. Seria ainda importante lembrar que a relação entre homossexualidade, imagem e meios de comunicação de massa precisar ser desenvolvida, mas há que se destacar O Personagem Homossexual no Cinema Brasileiro de Antonio Moreno, Homossexualidade: do Preconceito aos Padrões de Consumo de Adriana Nunan, A Forma Estranha e Homoeorotismo e Imagem no Brasil de Wilton Garcia, bem como os trabalhos em andamento de João Luiz Vieira, José Gatti e a publicação do volume coletivo Imagem e Diversidade Sexual.

Não devemos pensar a possibilidade de ampliação e consolidação desta nova área de estudos como simples recurso de jovens professores por espaço no mercado acadêmico brasileiro, que creio, dificilmente colocará esta questão como central nas suas discussões, a não ser que se sigam estratégias diferenciadas do Feminismo, ainda muito marcadas por um particularismo identitário, só mais recentemente aceitando analisar o feminino e o masculino como posições indissociáveis, atravessando tanto mulheres como homens.

Ainda, para compreender as ambivalência da homossexualidade masculina é de vital importância estar atento a trabalhos de viés marcadamente antropológico feitos recentemente sobre o travesti brasileiro, como os de Hélio Silva, Neuza de Oliveira, Don Kulick e Hugo Denizar. Longe de virar mera alegoria abstrata da transitividade sexual contemporânea, o travesti representou um primeiro espaço de visibilidade de uma subcultura gay, ainda que a ela não se restrinja. O diário 
de campo, penso aqui no trabalho de Hélio Silva, implica um repensar cotidiano, poético e sensível, no encontro de mundos inesperados, que vão além do palcos de Hollywood, de talk shows e programas de auditório sensacionalistas. Narrar, cartografar como opcão teórico-metodológica, ao invés de analisar distanciadamente podem abrir diálogos fecundos entre antropologia e arte contemporâneas como em Ana Cristina César de Ítalo Moriconi, em que biografia e autobiografia geracional, realidade e ficção se cruzam de forma fascinante e emocionada e o travestimento se torna uma importante chave de comprensão da obra da poeta carioca, nome que se destaca do cenário da poesia marginal dos anos setenta.

A preocupação com a masculinidade também é outro ponto fundamental de diálogo com os estudos gays, como os trabalhos de Sócrates Nolasco, Dario Caldas, João Silvério Trevisan, Fernando Gabeira, Míriam Goldenberg, Durval Muniz, Benedito Medrado entre outros. É necessário colocar cada vez mais em pauta a questão da masculinidade dentro das relações homossexuais bem como discutir mais a questão da homossexualidade dentro dos estudos sobre masculinidade. Novamente o diálogo entre antropologia e literatura contemporâneas pode nos dar pistas importantes. Da leitura deleuziana sobre a prostituição masculina, os michês, feita por Néstor Perlongher à obra de Caio Fernando Abreu, talvez o autor central no Brasil para ampliar esta discussão, em que o encontro amoroso entre homens dialoga com uma escrita despudoradamente sentimental, há um importante questionamento da afetividade no horizonte do masculino.

Também a obra de João Gilberto Noll é um importante repensar da solidariedade masculina dentro de uma ética da deriva, não só na amizade e no amor, mas na relação entre pai e filho, como na sua obra-prima Rastros de Verão, em que todo o redimensionamento de laços familiares é colocado sob o signo da instabilidade. Instabilidade que, como nos lembra Ítalo Moriconi em belo ensaio, vem da fragilidade das referências comunitárias e da ausência de laços organizados entre os indivíduos. Os encontros furtivos não se contrapõem culpadamente aos imperativos do amor romântico idealizador, nem se ocultam como frustrações de relações estáveis. Esta seria uma importante contribuição da literatura. Se a parceria civil entre pessoas do mesmo sexo tornou-se uma importante bandeira do movimento gay brasileiro, curiosamente a literatura brasileira, diferente da literatura norte-americana, apresenta em sua quase totalidade as relações afetivas e sexuais entre homens como marcadas pela rapidez do encontro, mesmo quando felizes (uma exceção recente seria Berkeley em Bellagio de João Gilberto Noll). Seria interessante pensar esta construção literária não como afirmação do clichê da homossexualidade associada à promiscuidade nem como um silenciamento, mas como uma alternativa afetiva para além da submissão a modelos tradicionais da família monogâmica estável.

Para lidar com esta última questão é que defendo uma política, uma ética e uma estética da homoafetividade. Não pretendo apenas cunhar mais um termo, mas penso 
que falar em homoafetividade é mais amplo do que falar em homossexualidade ou homoerotismo, vai além do centralidade da sexualidade, bem como é um termo mais sensível para apreender as fronteiras frágeis e ambíguas entre a homossexualidade e a heterossexualidade, construídas no século passado, sem também se restringir a uma homossociabilidade homofóbica, como em tantos espaços sociais que foram tradicional e exclusivamente masculinos como times de futebol, internatos, quartéis e bares. Uma política da homoafetividade busca alianças para desconstruir espaços de homossociabilidade homofóbicos ou heterofóbicos, ao mesmo tempo que pensa, num mesmo espaço, as diversas relações entre homens (ou entre mulheres), como entre pai e filho, entre irmãos, entre amigos, entre amantes.

Um outro exemplo de como a literatura pode falar o que os militantes e os discursos sociais reiteram ou silenciam é quando falamos sobre a pedofilia. A tradição lírica brasileira teria uma importante contribuição para a redução, feita com o aval dos meios de comunicação de massa, das relações entre homens adultos e adolescentes/menores à pornografia, violência e estupro. Um dos temas mais antigos na lírica ocidental, a pederastia homossexual se viu sem espaço pelo processo em que a pedofilia se transformou em verdadeira paranóia globalizada, fazendo com que ministros caiam, o papa se prenuncie, passeatas sejam feitas, mas pouco tem se falado de afeto consentido. Seria um novo velho puritanismo, o mesmo que ridicularizou Freud quando este afirma que todo bebê, longe do anjo idealizado, já possuía uma sexualidade polimorfa? Já que aos homens adultos que gostam de adolescentes e dos adolescentes que gostam de homens adultos foi lhes tirada a voz, gostaria de lembrar que também a tradição lírica pederasta atravessa a produção poética brasileira, como já se pode comprovar desde um soneto escrito por Mario de Andrade, em 1937, até vários trabalhos contemporâneos, como contraponto à construção demonizadora desta prática, como aliás foi feita em relação com a homossexualidade no século xIx.

Muitas são as opcões. O termo literatura gay enfrenta forte resistências entre críticos e, mesmos entre escritores brasileiros que não têm problemas com sua homossexualidade ou em apresentá-la em sua ficção. De minha parte, após passar por várias respostas a esta questão no meu recente livro, O Homem que Amava Rapazes e Outros Ensaios, fico com a conviç̧ão de que ser um "escritor, gay", para uma última vez assumir a formulação de Silviano Santiago, não se trata de apenas considerar a homossexualidade como um tema, uma representação social ou discurso que atravessa diferentes saberes, mas afirmar uma experiência que interliga vida e obra, sem reduzir a obra a um dado da biografia. A experiência gay nada tem de redutora ou classificadora, é um mistério insondável, implica uma ética, uma estética e uma espiritualidade. 
BibliografiA

Arenas, Fernando e Susan Quinlan, eds.. Lusosex. Minneapolis/Londres: U of Minnesota P, 2002. Utopias of Otherneess. Minneapolis/Londres: U of Minnesota P, 2003.

Berlant, Lauren e Elizabeth Freeman. “Queer Nationality”. Fear of a Queer Planet. Michael Warner, org. Minneapolis: U of Minnesota P, 1994.

Bessa, Marcelo Secron. Histórias Positivas. Rio de Janeiro: Record, 1997. Perigosos. Autobiografia e AIDS. Rio de Janeiro: Aeroplano, 2002.

Bhabha, Homi. “A Questão do 'Outro': Diferença, Discriminação e o Discurso do Colonialismo”. Pós-Modernismo e Política. Heloísa Buarque de Hollanda, org. Rio de Janeiro: Rocco, 1991.

O Local da Cultura. Belo Horizonte: Ed. da UFMG, 1998.

Campos, Maria Consuelo Cunha. De Frankenstein ao Transgênero. Rio de Janeiro: Ágora da Ilha, 2001.

Carvalho, Ana Maria Bulhões de. "Voyeur/Exibicionista e o Ethos Gay". 6 x 4 Máscaras do Narrador na Obra de Silviano Santiago. Tese de Doutorado. Rio de Janeiro: Universidade Federal do Rio de Janeiro, 1997.

Costa, Jurandir Freire. A Inocência e o Vício. Rio de Janeiro: Relume-Dumará, 1992.

Cruz-Malavé, Arnaldo. "Leciones de cubanía. Identidad nacional y errancia homosexual en Senel Paz, Martí e Lezama”. Revista de Crítica Cultural (noviembre 1998): 58-67.

Cult, 66, ano VI, fevereiro 2003.

Cunha, Eneida Leal. "Leituras da Dependência Cultural". Navegar é Preciso, Viver. Escritos para Silviano Santiago. Eneida Maria de Souza e Wander Melo Miranda, orgs. Belo Horizonte/Salvador/Niterói: Ed. da UFMG/EDUFBA/ EDUFF, 1997.

Daniel, Herbert e Leila Miccolis. Jacarés e Lobisomens. Rio de Janeiro: Achiamé,1983.

Edelman, Lee. Homographesis: Essays in Gay Literary and Cultural Theory. New York: Routledge, 1994.

Faury, Maria Lúcia. Uma Flor para os Malditos. São Paulo: Papirus, 1984.

Fichte, Hubert. The Gay Critic. Ann Arbor: U of Michigan P, 1996.

Foureaux, José Luís (org.). Literatura e Homoerotismo. São Paulo: Scortecci, 2002.

Garcia, Wilton. A Forma Estranha. São Paulo: Pulsar, 2000.

e Rick Santos (orgs.). A Escrita de Adé. Perspectivas Teóricas dos Estudos Gays e Lésbic@s no Brasil. São Paulo/New York: Xamã/SUNY, 2002. 
Homoerotismo e Imagem no Brasil. São Paulo: Nojosa, 2004.

et al. (orgs.). Imagem e Diversidade Sexual. São Paulo: Nojosa, 2004.

Green, James. Além do Carnaval. A Homossexualidade Masculina no Brasil do Século XX. São Paulo: Unesp, 2000.

Hecker Filho, Paulo. Um Tema Crucial. Porto Alegre: Sulina, 1989.

Larkosh, Cristopher. "Néstor e Caio: cartografias multilíngues” Caio Fernando Abreu - Palavra e Pessoa. Italo Moriconi, org. Manuscrito. 2000.

Lopes, Denilson. O Homem que Amava Rapazes e Outros Ensaios. Rio de Janeiro: Aeroplano, 2002.

Lopes Jr., Francisco Caetano. “Uma Subjetividade Outra”. Towards Socio-Criticism. in Roberto Reis, org. ASU at Tempe, Center for Latin-American Studies, 1991.

Lyra, Bernadette e Wilton Garcia (orgs.). Corpo e Cultura. São Paulo: Xamã/ ECA-USP, 2001.

Mais (Amores Expressos) in Folha de São Paulo, 30/3/2003.

McClintock, Anne. “'NoLonger in a Future Heaven': Gender, Race and Nationalism”. Dangerous Liaisons. 2a ed. Anne McClintock, et al., orgs. Minneapolis: U of Minnesotta P, 1998.

Míccolis, Leila e Daniel Herbert. Jacarés e Lobisomens. Rio de Janeiro: Achiamé, 1983.

Moreno, Antonio. O Personagem Homossexual no Cinema Brasileiro. Rio de Janeiro: Eduff/Funarte, 2001.

Moriconi, Ítalo. “Para Pensar o Homem-Ilha”. Revista Matraga 2/3 (UERJ, março/ dezembro 1987).

Ana Cristina César. O Sangue de uma Poeta. Rio de Janeiro: RelumeDumará, 1996.

Noll, João gilberto. Rastros de Verão. Rio de Janeiro: Rocco, 1990. Berkeley em Bellagio. Rio de Janeiro: Objetiva, 2002.

Nunan, Adriana. Homossexualidade: do Preconceito aos Padrões de Consumo. Rio de Janeiro: Caravansarai, 2003.

Parker, Richard. Abaixo do Equador. Rio de Janeiro: Record, 2002.

Posso, Karl.Artful Seduction. Homosexuality and the Problematics of Exile. Oxford: Oxford UP, 2003.

Santiago, Silviano. “OEntre-Lugar do Discurso Latino-Americano”. Uma Literatura nos Trópicos. São Paulo: Perspectiva, 1978. 11-28.

Em liberdade. Rio de Janeiro: Paz e Terra, 1981.

Stella Manhattan. Rio de Janeiro: Nova Fornteira, 1985.

Viagem ao México. Rio de Janeiro: rocco, 1996.

Keith Jarrett no Blue Note. Rio de Janeiro: Rocco, 1996. 
De cócoras. Rio de Janeiro: Rocco, 1999.

“O Homossexual Astucioso”. Brasil/Brazil XIII/23 (2000): 7-18.

O Falso Mentiroso. Rio de Janeiro: rocco, 2004.

O Cosmpolitismo do Pobre. Belo Horizonte: UFMG, 2005.

Histórias Mal Contadas. Rio de Janeiro: Rocco, 2005.

Schwarz, Roberto. "Nacional por Subtração". Que Horas São?. São Paulo: Companhia das Letras, 1987.

Sussekind, Flora. "Ficção 80: Dobradiças e Vitrines”. Papéis Colados. Rio de Janerio: Ed. da UFRJ, 1993.

Swain, Tânia Navarro. O Que é Lesbianismo. São Paulo: Brasiliense, 2000.

Trevisan, João Silvério. Devassos no Paraíso. A Homossexualidade no Brasil, da colônia à atualidade. 3a. ed., Rio de Janeiro, Record, 2000.

Yúdice, George. A Conveniência da Cultura: Usos da Cultura na Era Global [2003]. Marie-Anne Kremer, trad. Belo Horizonte: UFMG, 2006. 
